\title{
A Study of Comparison of Lung Function Test between Male and Female Young Adults
}

\author{
Authors \\ Dr Rahul Chandra Das ${ }^{1}$, Dr Wasima Jahan ${ }^{2}$ \\ ${ }^{1}$ Associate Professor, ${ }^{2}$ Professor \\ Department of Physiology, Assam Medical College, Dibrugarh, Assam, Pin-786002 \\ Email:drrahulchdas@yahoo.com
}

\begin{abstract}
The lung function tests are broad range of tests that provide an assessment of the respiratory system in terms of its function. There are a few variables such as age, gender and body size which have impact on the lung function test.

Aims and Objective: present study was done to compare the TV, IRV, ERV, VC, MVV, and PEFR between male and female subjects.

Materials and Method: the present study was conducted on 200 healthy young adults of $18-21$ years of age in around the Assam Medical College, Dibrugarh. Group I comprised of 120 healthy young males and Group II comprised of 80 healthy young females. TV, IRV, ERV, MVV were measured with Inco's double recording spirometer in conjunction with electric kymograph and PEFR was measure with mini wright peak flow meter. Results: in the present study out of the 200 subjects 180 were male and 20 were female. The mean TV, IRV, ERV, VC, MVV \& PEFR in male were $473.16 \pm 26.01 \mathrm{ml}, 1782.19 \pm 138.33 \mathrm{ml}, 1081.25 \pm 33.58 \mathrm{ml}$, $3337.92 \pm 157.28 \mathrm{ml}, 93.30 \pm 11.22 \mathrm{ml} \& 573.50 \pm 60.25 \mathrm{~L} / \mathrm{min}$ respectively and that of in female were $398.62 \pm 28.61 \mathrm{ml}, \quad 1259.75 \pm 49.92 \mathrm{ml}, 891.38 \pm 31.08 \mathrm{ml}, 2549.87 \pm 8467 \mathrm{ml}, 57.91 \pm 5.13 \mathrm{ml}, 424.50 \pm 39.60 \mathrm{~L} / \mathrm{min}$ respectively.

Conclusion: The present study showed a significant decrease in $T V, I R V, E R V, V C, M V V \&$ PEFR in female subjects which may due to difference in body structure in male and female subjects.

Abbreviations: TV tidal volume, IRV inspiratory reserve volume, ERV expiratory reserve volume, VC vital capacity, MVV maximum ventilatory volume, PEFR peak expiratory flow rate, PFT pulmonary function test, BMI body mass index.
\end{abstract}

\section{INTRODUCTION}

The lung function tests are broad range of tests that are usually done and consist of the performance of a set of manoeuvres to detect and quantitative disorders of pulmonary ventilation and gas exchange. They measure how well the lungs take in and exhale air and how efficiently they transfer oxygen in to the blood. They are used for diagnosis and prognosis of various lung disorders. Spirometry and peak flow meter are the most basic and widely used method for evaluating pulmonary function. There are few variables such as age, gender, and body size which have an impact on the lung function. Usually the lung volumes and capacities of males are larger than that of in females. Even when males and females are matched for height and weight males have larger lungs than females. 
Because of this gender dependent lung size difference, different normal table must be used for males and females. Before puberty the function of lung is nearly identical between boys and girls of equal size, though the vital capacity (VC) of the boys is on average $8 \%$ larger than that of girls and indices which relate to vital capacity also differ by this amount. Difference in size becomes more marked during adolescence due to mainly the growth in the thorax being grater in boys than girls. This change is mediated by the level of growth hormone in the blood which Brody and others have shown to contribute to size of the lungs. The strength of the muscles, including that of the thorax also becomes greater in boys. In accord with this finding Pierce and authors have evidence that in relation to their volume, the lungs of adult men contain less collagen tissue than the lungs of women. These changes have the effect of increasing the force which make for the expansion of the lung without a corresponding increase in the elastic recoil; they may explain why in relation to their body size the men have the larger lung. ${ }^{(1)}$

For references the standard laid down in the western country are not applicable to the people in the topical country like India having varied ethnic, climatic, cultural and socio-economic conditions. Data available on Indian people in different age group and sex from various parts of the country are limited and the easternmost part of India are specially lacking.

With a view to find out the different parameters the lung function tests was carried out among the healthy young adults.

\section{MATERIALS AND METHOD}

The study was conducted on 200 healthy young medical students of both sexes in age group of 1821 years. History was taken from each subject and each subject was clinically examined to exclude apparent cardio-vascular and respiratory disease. The subjects were devided into two groups. Group I comprised of 120 normal healthy young males. Group II comprised of 80 normal healthy young females. The subjects were seated on a high stool keeping his back towards the instrument to minimise psychic effect, and a nose clip was used. The tests were performed at various times of the day, but most were done between 10am to 12 noon. The ventilatory tests consisted of the vital capacity (VC), tidal volume (TV), inspiratory reserve volume (IRV), expiratory reserve volume (ERV), and maximum voluntary ventilation (MVV). Before doing the tests spirometer was filled with water $3 / 4$ th of the total length of the cylinder. Before doing the test the technique of the measurement were demonstrated to the subjects. At least two or three readings were taken and best effort was selected. The subjects were made to sit comfortable in a stool, nose was clipped and the mouthpiece was inserted between the teeth and the lips, now the subject was allowed to breath the room air this was done to make him familiar to breath through the mouthpiece with nose clipped. After a gap of one minute the free breathing valve was turned to connect the subject to spirometer and immediately the kymograph started at a speed of $60 \mathrm{~mm} / \mathrm{min}$ and normal breathing was recorded for about one minute. This was used for computing the tidal volume. The subject was then instructed to breath in with a maximal effort. He was also instructed before not to breath in, while he is breathing out. At least three such curves were obtained and maximum of the three values were taken for calculation purpose. Now the subjects were instructed to breathe in and out as rapidly and as deeply as he or she can for a period of 15 seconds keeping the kymograph at the same speed $(60 \mathrm{~mm} / \mathrm{min})$. The pulmonary ventilation thus calculated from the record called the maximum voluntary ventilation.

Peak expiratory flow rate was measured by using a Mini Wright Peak Flow Meter. After practical demonstration the subjects were asked to inspire as deeply as possible and blow as hard and quickly as possible in one short sharp blast in the peak flow meter. The indicator was stop at a figure on the scale and noted this reading. At least three reading were taken and the highest value out of the three was recorded. 


\section{RESULTS}

The present study comprised of 200 healthy subjects of either sex in the age group of 18-21years. Group I comprised of 120 male and Group II 80 female subjects.

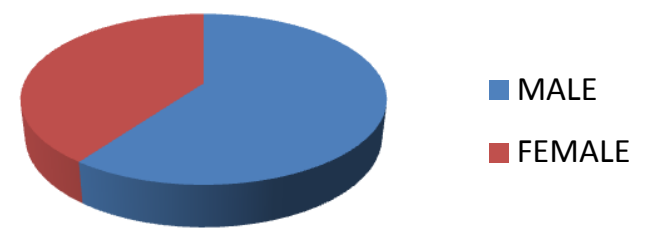

Fig 1: showing the distribution of male and female subjects in the study population.

In the present study in male the mean values are TV $473.16 \pm 26.01 \mathrm{ml}$, IRV $1782.19 \pm 138.33 \mathrm{ml}$, ERV $1081.25 \pm 33.58 \mathrm{ml}, \quad$ VC $3337.92 \pm 157.28 \mathrm{ml}$, and

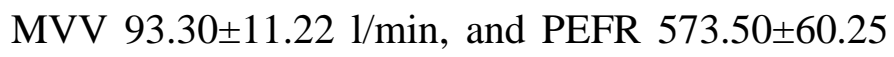
$1 / \mathrm{min}$; while in female subjects TV $398.62 \pm 28.61 \mathrm{ml}$, IRV 1259.75 \pm 49.92, ERV 891.38 $\pm 31.08, \quad V C$ $2549.87 \pm 84.67 \mathrm{ml}$, MVV 57.91 $\pm 5.131 / \mathrm{min}$, PEFR $424.50 \pm 39.601 / \mathrm{min}$. Which shows a greater parameters in male subjects in comparison to female subjects ( $\mathrm{p}$ value $<0.001$ ).

Table 1: showing the difference in lung function between male and female.

\begin{tabular}{|l|c|c|c|c|}
\hline \multirow{2}{*}{$\begin{array}{l}\text { Lung } \\
\text { parameters }\end{array}$} & \multicolumn{2}{|c|}{ MALE } & \multicolumn{2}{c|}{ FEMALE } \\
\cline { 2 - 5 } & MEAN & \pm SD & MEAN & \pm SD \\
\hline TV $(\mathrm{ml})$ & 473.16 & 26.01 & 398.62 & 28.61 \\
\hline IRV $(\mathrm{ml})$ & 1782.19 & 138.33 & 1259.75 & 49.92 \\
\hline ERV $(\mathrm{ml})$ & 1081.25 & 33.58 & 891.38 & 31.08 \\
\hline VC $(\mathrm{ml})$ & 3337.92 & 157.28 & 2549.87 & 84.67 \\
\hline MVV $(\mathrm{L} / \mathrm{min})$ & 93.30 & 11.22 & 57.91 & 5.13 \\
\hline PEFR (L/min) & 573.50 & 60.25 & 424.50 & 39.60 \\
\hline
\end{tabular}

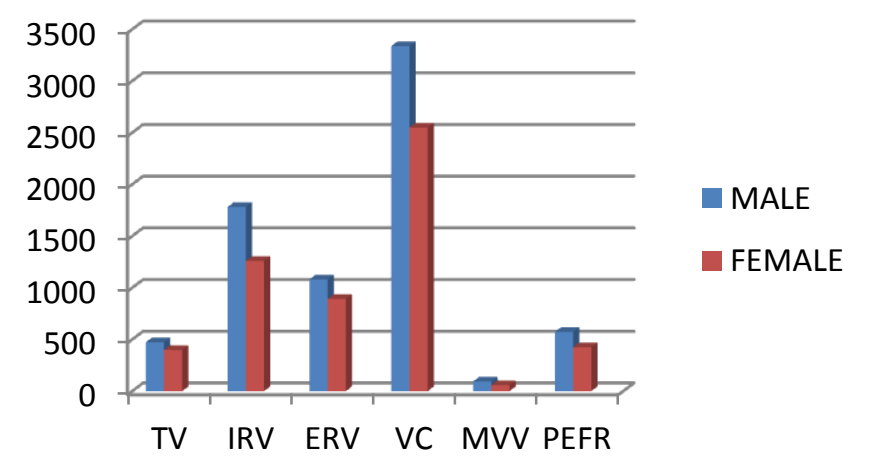

Fig: 2 showing the lung function parameter in male and female.

\section{DISCUSSION}

In the present study it has been found that lung function parameters (TV, ERV, IRV, MVV, and PEFR) are less female subjects than the male subjects. In the present study results are from a narrow age group between 18-20 years of age. This is age where the lung volumes are maximum. There is decline of different lung volumes after the age of 30 years.

Saikia T.C (1984) also found that the mean values of different lung parameter like TV, ERV, IRV, and MVV are higher in males than females. In this study mean values of TV, IRV, ERV, VC, MVV in males were 462,1393,1047, 2973, 82.09 respectively and that of in females were $395,889,709$, 1983, 59.76 respectively. In the present study all the values are higher than the values obtained by Saikia T.C. except the MVV in females. The higher values in our study may be due to better performance of the subjects, the time of the day when it was carried out and the various physical and environmental conditions. ${ }^{(2)}$

G. Grimby and B. Soderholm (1963) found the mean values of $\mathrm{VC}$ and $\mathrm{MVV}$ to be $4.89 \mathrm{~L}$ and $1.59 \mathrm{~L} / \mathrm{min}$ respectively in males and $3.38 \mathrm{~L}$ and $107 \mathrm{~L} / \mathrm{min}$ respectively in females. These values are higher than our present mean values. This must be difference of age they took the males of 20-65 years and females of 18-72 years but in our study the study the age group was in between 18-21years in both males and females. ${ }^{(3)}$

Whitfield, Waterhouse and Arnott (1950) in their study found the mean value of $\mathrm{VC}$ in males and females to be $4230 \mathrm{ml}$ and $3660 \mathrm{ml}$ respectively. In our present study the mean values of VC in males and females were $3337.92 \mathrm{ml}$ and $2549.87 \mathrm{ml}$ respectively. Bothe the study shows a decrease in $\mathrm{VC}$ in female in comparison with males. ${ }^{(4)}$

Malik et al measured PEFR in 414 healthy Indian males and females. It was observed that the highest PEFR in males were seen in the age group of 20-34 years, after that there was a slow decline in the PEFR of males. In women the PEFR was uniformly lower than in men of corresponding age, maximal 
values were observed in the age group of 25-29 years (PEFR353 \pm 32 ). ${ }^{(5)}$

Singh H.D measured PEFR in South Indian adults with Peak Flow Meter in 851 healthy men and women of two categories. Group1- students and staff of the medical college constitute the middle income group and Group2- healthy individuals from the poorer class with an income of less than 200/per month forming the lower income group. In both the categories women had much lower values than men and in both the sexes the values in the subjects of the poor income group was significantly lower. PEFR was found to correlate best with the height of the in the subjects below 30years and with age in older subjects. ${ }^{(6)}$

\section{CONCLUSION}

So in our present study we found that the lung function parameters were much higher in males than the female subjects which is due to the difference in the body structure and strength of the respiratory muscle between male and female. But further study correlating the age, height and weight with Lung function parameters of the individuals were necessary to laid down a standard lung function parameters of a particular population.

\section{ACKNOWLEDGMENT}

We are thankful to the principal cum chief superintendent Assam Medical College and Hospital for kindly allowing us to carry out my research work.

\section{REFERENCES}

1. Cotes J.E. Ward MP. Ventilation capacity in normal Butaness J. Physiol. Lond. 1966; 186:88-89.

2. Saikia T.C - personal communication.

3. Grimby G. and SoderholmB: Spirometric studies in normal subjects. III. static lung volumes and maximum voluntary ventilation in adults with a note on physical fitness. Acta. Med. Scand, 1963,173,199.

4. A.G.W. Whitfield, J.A.H. Waterhouse and W. Melvilli Arnott, Brit, J.Soc, Med (1950), 4,113-136.
5. Malik S.K, JindalS.K, Jindal V, and Bansal S: Peak expiratory flow rate in healthy adult Ind. J. Chest. Dis.1975:19: 166-71.

6. Singh H.D, Peri S. Peak Expiratory Flow Rate in South Indian Adult. Ind. J. Physio Pharmacol1979; 23: 315-20. 